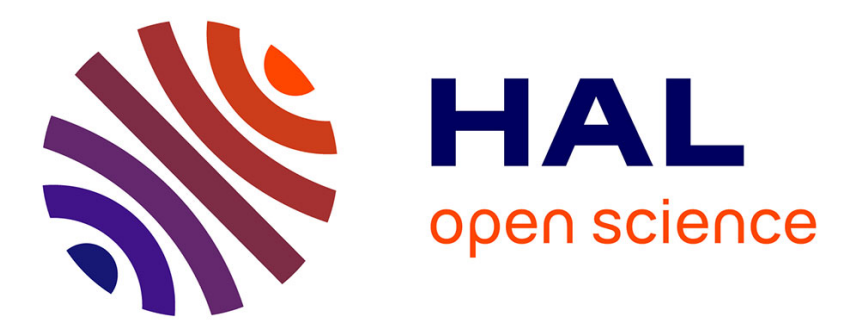

\title{
Mechanisms of Fibrinogen Adsorption on Silica Sensors at Various pHs: Experiments and Theoretical Modeling
} Monika Wasilewska, Zbigniew Adamczyk, Marta Sadowska, Fouzia Boulmedais, Michal Cieśla

\section{- To cite this version:}

Monika Wasilewska, Zbigniew Adamczyk, Marta Sadowska, Fouzia Boulmedais, Michal Cieśla. Mechanisms of Fibrinogen Adsorption on Silica Sensors at Various pHs: Experiments and Theoretical Modeling. Langmuir, 2019, 35 (35), pp.11275-11284. 10.1021/acs.langmuir.9b01341 . hal-02322826

\section{HAL Id: hal-02322826 \\ https://hal.science/hal-02322826}

Submitted on 6 May 2020

HAL is a multi-disciplinary open access archive for the deposit and dissemination of scientific research documents, whether they are published or not. The documents may come from teaching and research institutions in France or abroad, or from public or private research centers.
L'archive ouverte pluridisciplinaire HAL, est destinée au dépôt et à la diffusion de documents scientifiques de niveau recherche, publiés ou non, émanant des établissements d'enseignement et de recherche français ou étrangers, des laboratoires publics ou privés. 


\title{
Mechanisms of Fibrinogen Adsorption on Silica Sensors at Various pHs: Experiments and Theoretical Modeling
}

\author{
Monika Wasilewska, ${ }^{\dagger} \dagger$ (i) Zbigniew Adamczyk, ${ }^{* \dagger}{ }^{\dagger}$ Marta Sadowska, ${ }^{\dagger}$ Fouzia Boulmedais, ${ }^{\ddagger}$ \\ and Michał Cieśla ${ }^{\S}$
$\dagger$ Jerzy Haber Institute of Catalysis and Surface Chemistry Polish Academy of Sciences, Niezapominajek 8, 30-239 Kracow, Poland
${ }^{\ddagger}$ Institut Charles Sadron, Centre National de la Recherche Scientifique, Université de Strasbourg, 23 rue du Loess, 67034 Strasbourg Cedex 2, France
§Jagiellonian University, Faculty of Physics, Astronomy, and Applied Computer Science, ul. prof. Stanisława Łojasiewicza 11, 30-348 \\ Kracow, Poland
}

Supporting Information

ABSTRACT: The adsorption kinetics of human serum fibrinogen at silica substrates was studied using optical waveguide lightmode spectroscopy (OWLS) and quartz crystal microbalance (QCM) techniques. Measurements were

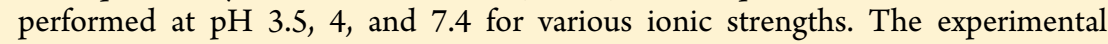
data were interpreted in terms of a hybrid random sequential adsorption model. This allowed the mass transfer rate coefficient for the OWLS cell and maximum coverages to be determined at various $\mathrm{pHs}$. The appearance of different, $\mathrm{pH}$ dependent mechanisms of fibrinogen adsorption on silica substrates was confirmed. At $\mathrm{pH} 3.5$ the molecules mostly adsorb in the side-on orientation that produces a low maximum coverage of ca. $1 \mathrm{mg} \mathrm{m}^{-2}$. At this $\mathrm{pH}$, the kinetics derived from the OWLS measurements agree with those theoretically predicted using the convective-diffusion theory. In consequence, a comparison of the OWLS and QCM results allows the water factor and the dynamic hydration of fibrinogen

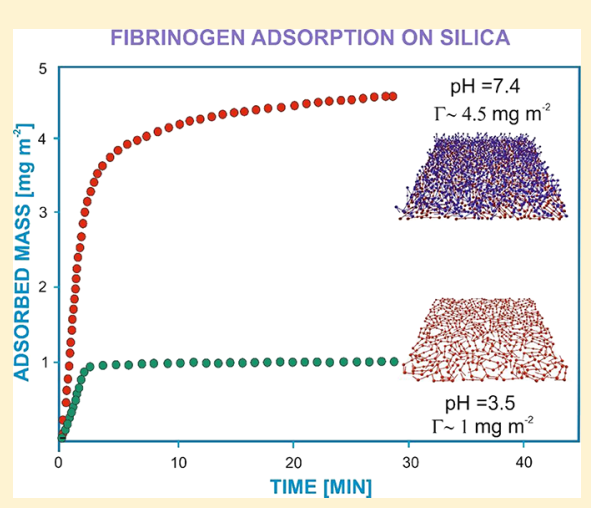
molecules to be determined. At pH 7.4, the OWLS method gives inaccurate kinetic data for the low coverage range. However, the maximum coverage that was equal to ca. $4 \mathrm{mg} \mathrm{m}^{-2}$ agrees with the QCM results and with previous literature results. It is postulated that the limited accuracy of the OWLS method for lower coverage stems from a heterogeneous structure of fibrinogen monolayers, which consist of side-on and end-on adsorbed molecules. One can expect that the results acquired in this work allow development of a robust procedure for preparing fibrinogen monolayers of well-controlled coverage and molecule orientation, which can be exploited for efficient immunosensing purposes.

\section{INTRODUCTION}

Fibrinogen, also referred to as Factor I, is a multifunctional glycoprotein which plays an essential role in the hemostatic system. ${ }^{1}$ In addition to a major function in blood clotting, fibrinogen plays a role in many physiological reactions including cellular and matrix interactions, neoplasia, or wound healing. Fibrinogen is also involved in platelet aggregation, regulations of Factor XIII (transglutaminase) activity, and inflammatory reactions. ${ }^{2}$ The concentration of fibrinogen in blood plasma varies between 2 to $4 \mathrm{~g} \mathrm{~L}^{-1}$.

Regarding the primary structure, the fibrinogen molecule is composed of two symmetric parts each consisting of three different polypeptide chains: $\mathrm{A} \alpha, \mathrm{B} \beta$, and $\gamma$. These polypeptide chains are assembled by intra- and interchain disulfide bonds and form a complex structure linked by two coiled-coil regions. The largest $\mathrm{A} \alpha$ chain of fibrinogen contains 610 amino acid residues (molar mass of $\sim 70 \mathrm{~kg} \mathrm{~mol}^{-1}$ ), and the $\mathrm{B} \beta$ chain consists of 461 amino acid residues (molar mass of $56 \mathrm{~kg}$ $\mathrm{mol}^{-1}$ ). The $\gamma$ chain is heterogeneous with respect to both size and charge. The most abundant form, denoted as $\gamma$, consists of
411 residues (molar mass of $48 \mathrm{~kg} \mathrm{~L}^{-1}$ ). This gives the net molar mass of the molecule equal to $338 \mathrm{~kg} \mathrm{~mol}^{-1}$. Assembly of the six separate chains takes place in the endoplasmic reticulum. $^{4-7}$

The fibrinogen molecule has a trinodular structure and a 2fold symmetry axis in its center, perpendicular to the long axis (see Supporting Information). The $\mathrm{A} \alpha, \mathrm{B} \beta$, and $\gamma$ chains are assembled with their $\mathrm{N}$ termini located in a central $\mathrm{E}$ nodule and extended outward in a coiled-coil region. The $\mathrm{B} \beta$ and $\gamma$ chains terminate in globular regions known as $\beta \mathrm{C}$ and $\gamma \mathrm{C}$ modules, which constitute the so-called D nodule. The $\mathrm{A} \alpha$ chains are the longest, at the end of the coiled-coil region, each chain extending into a highly flexible structure followed by a globular $\alpha \mathrm{C}$ region.

The shape and dimensions of the fibrinogen molecule were determined by Hall and Slayter ${ }^{8}$ by shadow-cast electron 
microscopy. More precise results were obtained by Veklich et al. ${ }^{9}$ who established that for $\mathrm{pH} 7.4$ the fibrinogen molecules assume a collapsed conformation with the $\alpha \mathrm{C}$ domains attached to the central nodule. At $\mathrm{pH} 3.5$, the molecule assumed a more expanded conformation with the flexible $\alpha \mathrm{C}$ chains directed under a right angle against the core part of the molecule. Yermolenko et al. ${ }^{10}$ and Protopopova et al. ${ }^{11}$ used atomic force microscopy (AFM) with large resolution to image single molecules of fibrinogen. They visualized the $\alpha \mathrm{C}$ regions along with complete domain structure.

These results were experimentally and theoretically confirmed in refs $12-14$ where a bead model of the fibrinogen molecule was developed by explicitly considering the presence of the flexible side arms ( $\alpha \mathrm{C}$ chains). The side chains are positively charged at $\mathrm{pH}$ range $3-10$ that facilitates fibrinogen molecule adsorption at various substrates. In the expanded state appearing at $\mathrm{pH}<4$ the effective molecule length is ca. 80 $\mathrm{nm}$ and at $\mathrm{pH} 7.4$ the length is equal to $48 \mathrm{~nm}$. In contrast to these considerable changes in the molecule length, the diffusion coefficient of the molecule remains practically constant within this $\mathrm{pH}$ range that furnishes the hydrodynamic diameter equal to $21 \mathrm{~nm} .{ }^{12}$ The isoelectric point of fibrinogen molecules is equal to $5.8 .^{15}$

Fibrinogen molecules exhibit a strong tendency to adsorb on various surfaces under a broad range of conditions ${ }^{16}$ mediating cellular interactions that are the key event in determining the biocompatibility of these materials. ${ }^{17}$ On the other hand, fibrinogen monolayers adsorbed on various synthetic materials may induce platelet adhesion that often leads to fouling of artificial organs. ${ }^{18,19}$

Because of its essential significance, fibrinogen adsorption on various substrates has been studied by a variety of experimental methods comprising ellipsometry, ${ }^{20,21}$ TIRF, $^{22}$ SPR, $^{23}$ $\mathrm{AFM}^{15,24-26}$ and streaming potential. ${ }^{26}$ The kinetics of fibrinogen adsorption under flow conditions can also be studied using the quartz crystal microbalance (QCM) technique. $^{20,29-32}$ However, a quantitative interpretation of obtained results is hindered because the frequency and dissipation signals provided by QCM stem from protein molecules and the trapped water. Its amount is a complicated function of molecule shape and orientations at substrates, monolayer coverage, substrate roughness, ${ }^{33}$ oscillation frequency, etc. $^{27-29,31,32}$ In refs 34 and 35, an efficient approach was developed enabling a quantitative interpretation of the QCM measurements where the amount of trapped water (hydration degree) in the adsorbed protein layer is calculated as the difference between the QCM mass and the dry mass derived from the solution of the governing convective-diffusion equation. In this way, the hydration of fibrinogen ${ }^{34}$ and human serum albumin molecules ${ }^{35}$ as a function of the coverage on silica sensors was explicitly determined.

A useful technique that can be exploited for measuring adsorption/desorption kinetics of proteins is the optical lightmode waveguide spectroscopy (OWLS), which is characterized by the sensitivity of the order of $10^{-2} \mathrm{mg}$ $\mathrm{m}^{-2} \cdot{ }^{20,36-43}$ For example, F. Höök et al. ${ }^{20}$ measured the adsorption kinetics of fibrinogen and other proteins on the $\mathrm{TiO}_{2}$ surface for $10 \mathrm{mM}$ HEPES buffer at $\mathrm{pH}$ 7.4. Except for OWLS, two different experimental techniques have been used.

Kurrat et al. ${ }^{42}$ used this method to determine the kinetics of adsorption of albumins (bovine and human) on the $\mathrm{Si}(\mathrm{Ti}) \mathrm{O}_{2}$ substrate. The irreversibly adsorbed mass of HSA at $\mathrm{pH} 7.4$ (HEPES buffer, $0.01 \mathrm{M}$ ) was equal to $1.7 \mathrm{mg} \mathrm{m}^{-2}$.
Sander et al. ${ }^{43}$ combined QCM and OWLS techniques to characterize protein adsorption on bare and poly-L-lysine (PLL) modified silica $\left(\mathrm{SiO}_{2}\right)$. The bovine serum albumin (BSA) was used as a reference protein. The maximum 'wet' mass on the $\mathrm{SiO}_{2}$ surface derived from QCM measurements was equal to $5.8 \mathrm{mg} \mathrm{m}^{-2}$ at $\mathrm{pH} 5$ and $2 \mathrm{mg} \mathrm{m}^{-2}$ at $\mathrm{pH} 7$ (for a $10 \mathrm{mM} \mathrm{NaCl}$ concentration). The adsorbed mass from OWLS was equal to 2.1 and $0.18 \mathrm{mg} \mathrm{m}^{-2}$ at $\mathrm{pH} 5$ and 7, respectively.

Interesting OWLS measurements for flagellin (a bacteria filament building protein) adsorption on silanized silica sensors were performed by Kovacs et al. $^{44}$ A quasi-isotropic model developed by Kovacs et al. ${ }^{45}$ based on the assumption of an average refractive index allowed calculation of the thickness of adsorbed protein layers and their birefringence. This confirmed a heterogeneous structure of the flagellin molecule and its preferred orientation in the adsorption layer. In another work, Kovacs et al. ${ }^{46}$ investigated, using OWLS, the kinetics of flagellin adsorption/desorption on the modified silica sensor. The experimental data were analyzed in terms of a theoretical model postulating different orientations of the molecule in the adsorbed layer. Using a numerical fitting procedure, the adsorption and desorption kinetic constants were determined as well as the free energy of adsorption, which significantly varied with the kind of electrolyte used in the experiments. However, in this kinetic modeling, the adsorption constants and maximum coverage of the protein (footprint area) were fitting parameters, which did not allow determination of, in a unique way, the range of applicability of the OWLS method for kinetics studies of anisotropic protein adsorption.

In another paper by Kovacs et al. ${ }^{47}$ analytical and numerical calculations were performed in order to investigate OWLS signals in the case of incomplete adlayers and inhomogeneous refractive index with respect to the coordinate perpendicular to the OWLS sensor surface. They predict significant deviations in the calculated optogeometrical parameters for such adlayers in comparison with homogeneous layers.

Elucidating this issue is the main goal of this work where thorough experimental measurements are carried out using a combination of the OWLS and the QCM methods for fibrinogen whose molecule can adsorb under various orientations at solid substrates. The experimental data are quantitatively interpreted in terms of a hybrid mass transfer model where the mean-field bulk transport equation is combined with surface mass transport described using the coarse-grained random sequential adsorption (RSA) model. Using this approach, blocking functions and maximum coverages pertinent to various orientations of adsorbing molecules are derived that allow for a quantitative interpretation of experimental data. In this way, the range of applicability of the OWLS method for quantitative studies of anisotropic protein adsorption can be estimated. The hydration function of fibrinogen molecules is also determined that facilitates a proper interpretation of QCM results.

\section{EXPERIMENTAL SECTION}

Fibrinogen from human blood plasma, fractions I, type I-S in the form of crystalline powders containing $50-70 \%$ protein, $25 \%$ sodium chloride, and $15 \%$ sodium citrate (Sigma F3879), was used in all experiments. Fibrinogen solutions were prepared by dissolving an appropriate amount of the crystalline powder under gentle stirring at appropriate $\mathrm{pH}$ and $298 \mathrm{~K}$ in a sodium chloride solution. Afterward, the suspension was passed through the $0.45 \mu \mathrm{m}$ filter to eliminate aggregates and impurities and the bulk concentration of fibrinogen was spectrophotometrically determined using a Shimadzu UV-1800 
spectrophotometer. The concentrated solutions (typically 300-500 $\mathrm{mg} \mathrm{L}^{-1}$ ) were diluted by a sodium chloride solution to the desired bulk concentration, usually $5-20 \mathrm{mg} \mathrm{L}^{-1}$, prior to each OWLS and QCM run.

The $\mathrm{pH}$ of the fibrinogen solution was regulated by the addition of $\mathrm{HCl}$ or $\mathrm{NaOH}$. However, for $\mathrm{pH} 7.4$ the PBS (phosphate buffered saline) and HEPES buffers were used to stabilize the $\mathrm{pH}$. The ionic strength was adjusted by the addition of $\mathrm{NaCl}$.

All chemical reagents such as sodium chloride and hydrochloric acid were commercial products of Sigma-Aldrich and were used without further purification. Ultrapure water was obtained using the Milli-Q Elix\&Simplicity 185 purification system from Millipore.

The diffusion coefficient of fibrinogen molecules was determined by dynamic light scattering (DLS) using the Zetasizer Nano ZS instrument (Malvern). The hydrodynamic diameter was calculated from the Stokes-Einstein equation. The electrophoretic mobility of fibrinogen molecules was measured using the Laser Doppler Velocimetry (LDV) technique also using the Zetasizer Nano ZS. The zeta potential was calculated from the Henry equation.

The kinetics of fibrinogen adsorption was determined using the Optical Waveguide Lightmode Spectroscopy (OWLS) and the quartz crystal microbalance (QCM) techniques. The former experiments were performed using the OWLS 210 instrument (Microvacuum Ltd., Budapest, Hungary), equipped with a laminar slit shear flow cell, holding a silica-coated waveguide (OW2400, Microvacuum). The adsorbing substrates were planar optical waveguides (OW 2400 from MicroVacuum, Budapest, Hungary) made of a glass substrate (refractive index $n_{S}=1.526$ ) covered by a film of $\mathrm{Si}_{0.78} \mathrm{Ti}_{0.22} \mathrm{O}_{2}$ of the thickness $170 \mathrm{~nm}$, and the refractive index $n_{F}=1.8$. A grating embossed in the substrate enables the light to be coupled into the waveguide layer. The sensor surface was coated with an additional layer $(10 \mathrm{~nm})$ of pure $\mathrm{SiO}_{2}$. A diffractive grating on the surface of the waveguide incouples $\mathrm{He}-\mathrm{Ne}$ laser light at two well-defined incident angles for the transverse electric (TE) and magnetic (TM) polarization modes. ${ }^{48}$ Different models described in the Supporting Information were used in order to calculate the mass of adsorbed protein.

The QCM measurements were carried out according to the standard procedure described in ref 34,49 , and 50 using the quartz/ silicon dioxide $\left(\mathrm{SiO}_{2}\right)$ sensors delivered by QSense, Gothenburg, Sweden. The sensors were cleaned before each experiment in a mixture of $96 \%$ sulfuric acid $\left(\mathrm{H}_{2} \mathrm{SO}_{4}\right)$, hydrogen peroxide $(30 \%)$, and pure water in the volume ratio $1: 1: 1$ for $2 \mathrm{~min}$. Afterward, the sensor was rinsed by deionized water at $80{ }^{\circ} \mathrm{C}$ for $30 \mathrm{~min}$ and dried out in a gentle stream of nitrogen gas. The roughness of sensors was examined by atomic force microscopy (AFM) imaging carried out in a semicontact mode under ambient conditions. It was confirmed that the sensors were smooth exhibiting the root-mean-square roughness equal to $0.80 \mathrm{~nm}$.

The adsorbed fibrinogen molecule mass per unit area (coverage), hereafter referred to as the QCM mass (coverage), was calculated from the Sauerbrey equation ${ }^{29,49,50}$

$$
\Delta m=-C_{\mathrm{Q}} \frac{\Delta f}{n_{\mathrm{o}}}
$$

where $\Delta m$ is the mass per unit area change, $\Delta f$ is the frequency change, $n_{\mathrm{o}}$ is the overtone number, and $C_{\mathrm{O}}$ is the mass (coverage) sensitivity constant equal to $0.177 \mathrm{mg} \mathrm{m}^{-2} \mathrm{~Hz}^{-1}$ for the $5 \mathrm{MHz}$ ATcut quartz sensor. ${ }^{34,51-55}$

\section{THEORETICAL MODELING}

The adsorption kinetics of fibrinogen were described using the efficient random sequential adsorption (RSA) model belonging to the class of coarse-grained Monte Carlo methods. The real shape of the molecule is approximated by a configuration of touching nodules (beads) of various size; ${ }^{13}$ see the Supporting Information. In this way, the surface blocking functions and the jamming coverage for various protein orientations at the surface were explicitly calculated and interpolated by analytical expressions in the form of low order polynomials. These were used as boundary conditions for the bulk transport convectivediffusion equation governing fibrinogen adsorption in the OWLS cell. This approach is also described in the Supporting Information.

\section{RESULTS AND DISCUSSION}

4.1. Bulk Fibrinogen and Silica Substrate Characteristics. Initially, basic physicochemical characteristics of fibrinogen molecules and the stability of its solutions were determined. This comprised the diffusion coefficient, hydrodynamic diameter, electrophoretic mobility, and zeta potential. The diffusion coefficient measured by DLS denoted by $D_{\infty}$ equal to $(2.0 \pm 0.1) \times 10^{-7} \mathrm{~cm}^{2} \mathrm{~s}^{-1}$ for an ionic strength range of $10^{-3}-10^{-2} \mathrm{M}, \mathrm{pH} 3.5$, and a temperature of $298 \mathrm{~K}$. At $\mathrm{pH}$ 7.4 and the same ionic strength, the range of the diffusion coefficient was equal to $(2.1 \pm 0.1) \times 10^{-7} \mathrm{~cm}^{2} \mathrm{~s}^{-1}$. Accordingly, the hydrodynamic diameter of fibrinogen calculated from the Stokes formula was equal to $21 \pm 0.5$ and $20 \pm 0.5 \mathrm{~nm}$ at $\mathrm{pH} 3.5$ and 7.4, respectively (ionic strength range of $10^{-2}-0.15 \mathrm{M}$ ).

The electrophoretic mobility of fibrinogen molecules directly measured using the LDV method was positive at $\mathrm{pH}$ 3.5 and $\mathrm{pH} 4$ and equal to 1.92 and $1.23 \mu \mathrm{m} \mathrm{cm} \mathrm{s}{ }^{-1} \mathrm{~V}^{-1}$, respectively (for ionic strength of $10^{-2} \mathrm{M}$ ). This corresponds to the zeta potential of fibrinogen molecules equal to 24 and 16 $\mathrm{mV}$, respectively. On the other hand, at $\mathrm{pH} 7.4$ the electrophoretic mobility was negative, equal to -1.28 and $-0.5 \mu \mathrm{m} \mathrm{cm} \mathrm{s}^{-1} \mathrm{~V}^{-1}$ for $I=10^{-2}$ and $0.15 \mathrm{M}$, respectively, that corresponds to a zeta potential of -17 , and $-6.4 \mathrm{mV}$, respectively. In the case of the $\mathrm{PBS}$ buffer at $\mathrm{pH} 7.4$, the fibrinogen zeta potential was equal to -15 and $-7.5 \mathrm{mV}$ for an ionic strength of $10^{-2}$ and $0.15 \mathrm{M}$, respectively. The dependence of the fibrinogen zeta potential on $\mathrm{pH}$ is graphically presented in Figure 1.

In order to properly interpret the adsorption kinetic measurements, it is also necessary to know the physicochemical characteristics of the silica substrate. Since it is not feasible

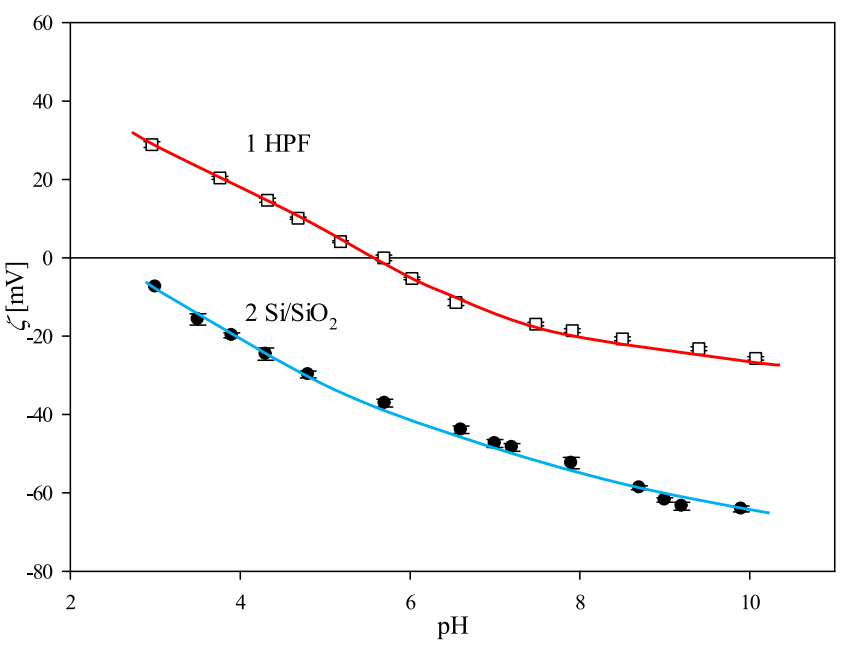

Figure 1. Dependence of the zeta potential on $\mathrm{pH}$ for ionic strength $10^{-2} \mathrm{M}$ : (1) fibrinogen molecules (HPF) in the bulk determined by LDV method; (2) the $\mathrm{Si} / \mathrm{SiO}_{2}$ substrate derived from streaming potential measurements. The solid lines represent nonlinear fits of experimental data. 
to directly determine the zeta potential of the silica sensor, thorough measurements were performed for oxidized $\mathrm{Si} / \mathrm{SiO}_{2}$ wafers by applying the streaming potential measurements. As shown in Figure 1, the zeta potential of the substrate was negative for all $\mathrm{pHs}$ studied, varying between -16 and $-49 \mathrm{mV}$ at $\mathrm{pH} 3.5$ and 7.4, respectively (for $I=10^{-2} \mathrm{M} \mathrm{NaCl}$ ). Accordingly, the charge density of the silica substrate calculated from the Gouy-Chapman formula varied between -0.023 and $-0.18 e \mathrm{~nm}^{-2}$ for these $\mathrm{pHs}$. The dependence of the $\mathrm{Si} / \mathrm{SiO}_{2}$ substrate zeta potential on $\mathrm{pH}$ is also shown in Figure 1.

4.2. Kinetics of Fibrinogen Adsorption. In the first series of OWLS measurements, the mass transfer rate constant $k_{c}$ for the cell was determined. It is a parameter of basic significance for assessing the validity of this method to determine kinetic of protein adsorption. Primarily, in these experiments, the dependence of fibrinogen surface density expressed in $\mathrm{mg} \mathrm{m}^{-2}$ (and denoted hereafter by $\Gamma$ ) on the adsorption time was measured for different flow rates and bulk concentrations. The measurements were carried out at $\mathrm{pH} 3.5$ where the fibrinogen molecules are expected to adsorb side-on forming a homogeneous layer of low thickness. ${ }^{13,34}$ It was observed that, after a short transition time (lasting typically a few seconds), the coverage vs the time dependencies became linear and proportionally increased with the bulk protein concentration. A typical experimental run recorded for the bulk fibrinogen concentration of $10 \mathrm{mg} \mathrm{L}^{-1}$, with the $\mathrm{NaCl}$ concentration equal to $0.01 \mathrm{M}$ and the flow rate equal to 2.5 $\times 10^{-3} \mathrm{~cm}^{3} \mathrm{~s}^{-1}$, is shown in Figure 2. For the OWLS cell, the

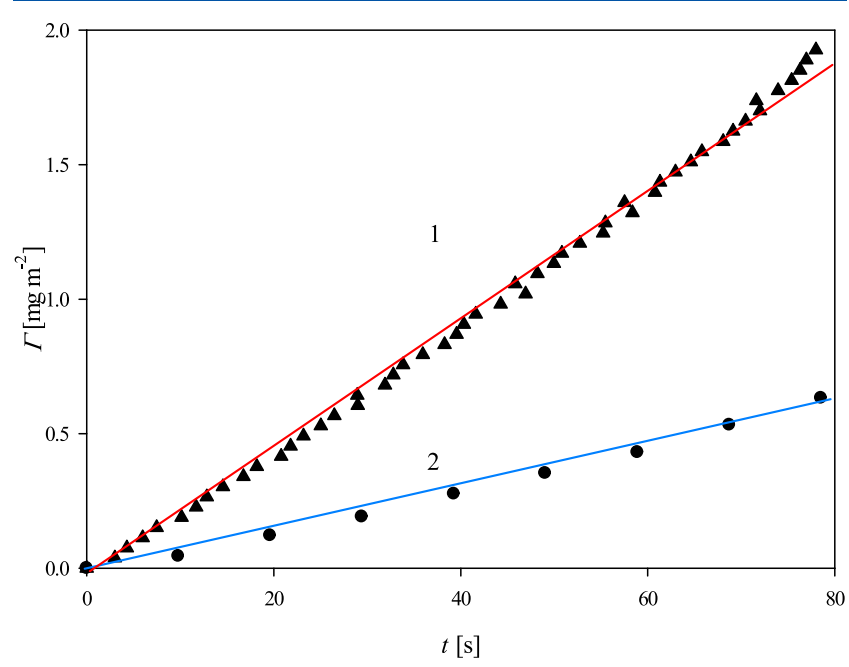

Figure 2. Dependence of the fibrinogen mass coverage at the silica sensor $\Gamma$ on the adsorption time determined by QCM (triangles) and OWLS (circles) for $\mathrm{pH} 3.5,0.01 \mathrm{M} \mathrm{NaCl}$, the bulk fibrinogen concentration $10 \mathrm{mg} \mathrm{L}^{-1}$, and the flow rate $2.5 \times 10^{-3} \mathrm{~cm}^{3} \mathrm{~s}^{-1}$. The solid lines show linear fits of experimental data (points) for QCM (red line number 1) and OWLS (blue line number 2).

slope $s_{l}$ of the linear dependence approximating experimental data is equal to $8.3 \times 10^{-3} \mathrm{mg} \mathrm{m}^{-2} \mathrm{~s}^{-1}$, which corresponds to the mass transfer rate constant $k_{c}=s_{l} / c_{b}=8.3 \times 10^{-5} \mathrm{~cm} \mathrm{~s}^{-1}$. Analogous linear dependencies were observed for other bulk concentrations and flow rates. This indicates that fibrinogen adsorption for the low coverage regime was bulk transport controlled. These results allowed the following interpolation formula describing the mass transfer rate constant to be established:

$$
k_{\mathrm{c}}=k_{\mathrm{c}}^{0} Q^{1 / 3} D_{\infty}^{2 / 3}
$$

where $k_{\mathrm{c}}^{0}=19 \pm 2 \mathrm{~cm}^{-4 / 3}$ and $Q$ is the volumetric flow rate in the cell.

Analogous expression was previously derived for the QCM cell used in this work where $k_{\mathrm{c}}^{0}=19.9 \mathrm{~cm}^{-4 / 3} \cdot{ }^{34}$

It is interesting to compare this semiempirical formula with the theoretical one pertinent to stationary mass transfer rate in the OWLS parallel-plate channel cell, which has the length $L=$ $0.8 \mathrm{~cm}$ (distance between the inlet and the outlet holes), the width $c=0.2 \mathrm{~cm}$, and the thickness $2 b$ equal to $0.03 \mathrm{~cm}$. Considering with these cell dimensions one can calculate the average mass transfer rate constant from the formula ${ }^{54}$

$$
\left\langle k_{c}\right\rangle=0.925 \frac{Q^{1 / 3} D_{\infty}^{2 / 3}}{b^{2 / 3} c^{1 / 3} L^{1 / 3}}=28.0 Q^{1 / 3} D_{\infty}^{2 / 3}
$$

On the other hand, the local mass transfer constant at the distance $l=0.5 \mathrm{~cm}$ from the inlet (where the protein adsorption is monitored by the optical system of the OWLS) is described by the one that has the expression

$$
k_{c}=0.616 \frac{Q^{1 / 3} D_{\infty}^{2 / 3}}{b^{2 / 3} c^{1 / 3} l^{1 / 3}}=21.8 Q^{1 / 3} D_{\infty}^{2 / 3}
$$

It should be mentioned that eqs 3 and 4 are strictly valid for a parallel-plate channel where the $b / c$ parameter is much smaller than unity.

Note that eq 4 agrees with the empirical formula expressed by eq 2 . A slight difference in the prefactor value can be attributed to the deviation of the real flow pattern in the OWLS cell from the flow pattern in the parallel-plate channel.

The OWLS and QCM kinetic data are compared in Figure 2 in order to obtain the water factor $w_{0}$ and the hydration function $\mathrm{H}_{0}$ of fibrinogen for the low coverage regime. As seen, the QCM coverage also linearly increases with the time and the slope of this dependence is equal to $2.5 \times 10^{-2} \mathrm{mg} \mathrm{m}^{-2} \mathrm{~s}^{-1}$ that corresponds to wet mass transfer rate constant $k_{c Q}=2.5 \times 10^{-4}$ $\mathrm{cm} \mathrm{s}^{-1}$

The OWLS and QCM mass transfer constants allow calculation of the water factor and the hydration function from the constitutive dependencies: ${ }^{35}$

$$
\begin{gathered}
w_{0}=\frac{\Gamma_{Q}(t)}{\Gamma(t)}=\frac{k_{c Q}}{k_{c}} \\
H_{0}=1-\frac{1}{w_{0}}
\end{gathered}
$$

where $\Gamma_{Q}$ and $\Gamma$ are the fibrinogen coverages derived from QCM and OWLS, respectively.

Using the above-derived values of $k_{c Q}$ and $k_{c}$ one obtains $w_{0}$ $=3.0$ and $H_{0}=0.67$, which agrees within error bounds with the previously obtained results ${ }^{34}$ where the dry mass of fibrinogen was theoretically calculated solving the convective-diffusion equation. This suggests that the OWLS measurements of fibrinogen adsorption at $\mathrm{pH} 3.5$ furnish accurate values of the protein coverage as a function of time, i.e., that can be exploited for calculating the absolute mass transfer rates in the cell.

In order to study this issue in more detail, another series of experiments were performed where the entire adsorption/ desorption kinetics of fibrinogen at $\mathrm{pH} 3.5$ were monitored by OWLS and QCM. The results shown in Figure 3a indicate that, initially, for fibrinogen coverage below $0.8 \mathrm{mg} \mathrm{m}^{-2}$ the 
a)

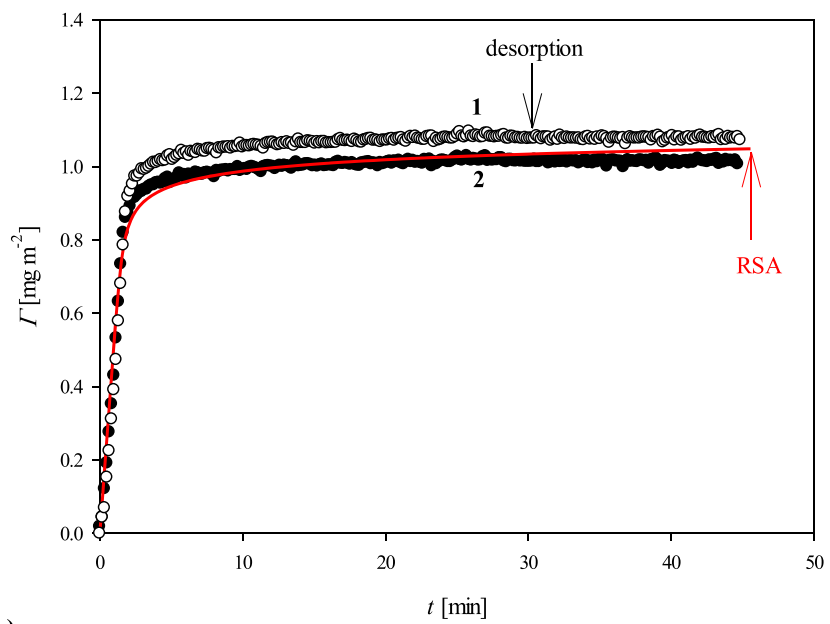

b)

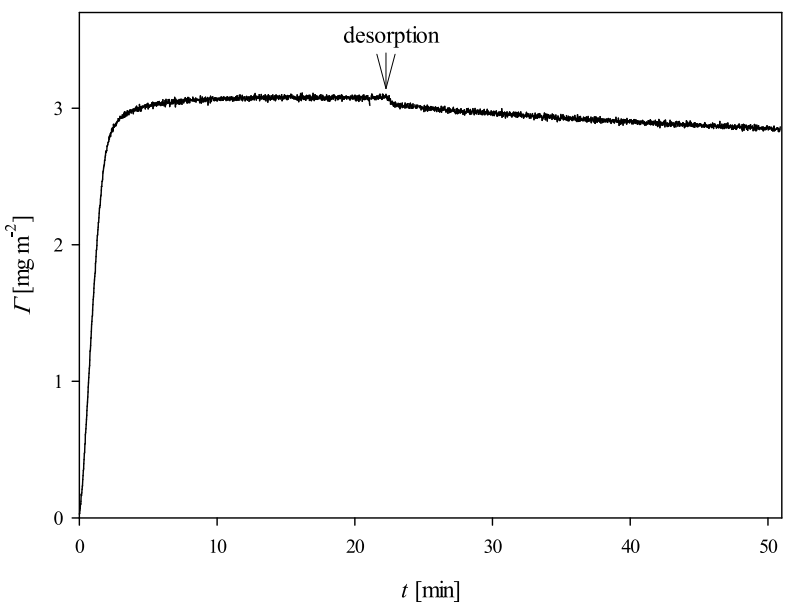

Figure 3. Kinetics of fibrinogen adsorption on silica; bulk protein concentration $10 \mathrm{mg} \mathrm{L}^{-1}, \mathrm{pH} 3.5,0.01 \mathrm{M} \mathrm{NaCl}$, flow rate $2.5 \times 10^{-3}$ $\mathrm{cm}^{3} \mathrm{~s}^{-1}$. (a) OWLS measurements; the open symbols (O) show the mass coverage calculated from the numerical procedure described in ref 56; the full symbols $(\bullet)$ show the results calculated using the homogeneous and isotropic adlayer model, and the red solid line shows the theoretical results derived by numerical integration of eq 6 . The inset $(1000 \mathrm{~nm} \times 1000 \mathrm{~nm})$ shows the fibrinogen molecule monolayer derived from RSA modeling (side-on adsorption with crossings). (b) QCM measurements. In both cases, the arrows show the beginning of the desorption run.

adsorption kinetic is a linear function of time characterized by the slope of $0.52 \mathrm{mg} \mathrm{m}^{-2} \mathrm{~min}^{-1}$. For $t>5 \mathrm{~min}$ the kinetics become considerably slower and a liming coverage equal to 1.0 $\mathrm{mg} \mathrm{m}^{-2}$ is attained. At the time of $30 \mathrm{~min}$ the desorption run was initiated by flushing pure electrolyte having the same ionic strength and $\mathrm{pH}$. As seen, only a negligible fraction of fibrinogen amounting to ca. $0.05 \mathrm{mg} \mathrm{m}^{-2}$ was desorbed. This indicates that the irreversibly adsorbed fraction of fibrinogen at this $\mathrm{pH}$ determined by OWLS is equal to $0.95 \mathrm{mg} \mathrm{m}^{-2}$. One should also observe that the difference in the results obtained using the homogeneous and isotropic adlayer model (full symbols in Figure 3 a) and the more general quasihomogeneous model for thick adlayer (open symbols in Figure 3 a) do not exceed $0.1 \mathrm{mg} \mathrm{m}^{-2}$ for the entire adsorption desorption run. It is also interesting to mention that analogous runs as that shown in Figure 3a were previously observed for flagellin molecules ${ }^{44}$ and human serum albumin. ${ }^{55}$
These experimental data were interpreted in terms of the hybrid random sequential adsorption (RSA) model as described in the Supporting Information. According to this model, the coverage (dry mass) of adsorbed fibrinogen molecules is governed by the formula

$$
\int_{\Gamma_{0}}^{\Gamma} \frac{\left(k_{\mathrm{a}}-k_{c}\right) B\left(\Gamma^{\prime}\right)+k_{c}}{k_{a} c_{b} B\left(\Gamma^{\prime}\right)-k_{d} \Gamma^{\prime}} \mathrm{d} \Gamma^{\prime}=k_{c} t
$$

where $\Gamma$ is the time-dependent coverage, $\Gamma_{0}$ is the initial coverage of the protein, $\Gamma^{\prime}$ is the dummy integration variable, $k_{\mathrm{a}}$ and $k_{\mathrm{d}}$ are the kinetic adsorption and desorption constants, $k_{c}$ is the mass transfer rate constant, and $B(\Gamma)$ is the surface blocking function that was derived by extensive modeling for various protein adsorption regimes. ${ }^{13}$

In the case of irreversible adsorption, where $k_{\mathrm{d}}=0$, the calculation of fibrinogen coverage from eq 6 does not require any fitting parameters because the mass transfer rate constant was determined above and the adsorption constant $k_{\mathrm{a}}$ can be calculated knowing the diffusion coefficient of the characteristic dimension of the molecule. ${ }^{54}$

One can observe that the theoretical results obtained by a numerical integration of eq 6 (shown in Figure 3a as the solid line) agree with experimental data for the entire range of adsorption time. Additional adsorption/desorption kinetic runs were performed for other bulk fibrinogen concentrations and flow rates that give an average value of the maximum coverage equal to $0.90 \pm 0.1 \mathrm{mg} \mathrm{m}^{-2}$ at $\mathrm{pH} 3.5$ and $0.01 \mathrm{M} \mathrm{NaCl}$ concentration (see Table 1). This agrees within error bounds with the theoretical result derived from the RSA modeling where a side-on orientation of fibrinogen molecules with crossings is assumed (see the inset in Figure 3a). In this case, the average maximum coverage varied between 0.79 and 0.82 $\mathrm{mg} \mathrm{m}{ }^{-2}$ depending on the molecule conformation. ${ }^{13}$ The conclusion of side-on adsorption at $\mathrm{pH} 3.5$ is further confirmed by the fact that the average fibrinogen monolayer thickness is $5.7 \mathrm{~nm}$ that agrees with the size of the beads used in the fibrinogen model equal to $5.3-6.7 \mathrm{~nm}$.

These facts support the hypothesis that the OWLS method furnishes quantitative kinetic data of a homogeneous protein monolayer of a low thickness. This behavior was also previously observed for HSA monolayers. ${ }^{55}$

In order to test the validity of this conclusion, complementary QCM measurements were performed at the same $\mathrm{pH}$, ionic strength, and flow rates. A typical kinetic run recorded in these measurements is shown in Figure $3 \mathrm{~b}$. One can observe that the QCM kinetics show the same trends as the OWLS kinetics and are characterized by an abrupt and linear increase in the fibrinogen coverage and at a time smaller than $5 \mathrm{~min}$. Afterward, a plateau value of the coverage is attained equal to $3.1 \mathrm{mg} \mathrm{m}^{-2}$. After switching to the desorption run, the fibrinogen coverage attains $2.8 \mathrm{mg} \mathrm{m}^{-2}$, which can be attributed to the irreversibly bound fraction of the protein. It should be mentioned that this value is 2.9 times larger than the coverage obtained by OWLS. Hence the water factor $w$ at the "dry" fibrinogen coverage equal to $1 \mathrm{mg} \mathrm{m}^{-2}$ is 2.9 and the hydration function $H=1-1 / w$ is equal to 0.65 .

The dependence of the hydration function on the "dry" coverage derived from OWLS is presented in Figure 4. The experimental results obtained in this work (points) are compared with the previous results obtained in ref 34 using the alternative method where the QCM coverage is compared with the "dry" coverage theoretically predicted from the 
Table 1. Maximum Coverage of Irreversibly Adsorbed Fibrinogen Determined at Various pHs by OWLS and QCM

\begin{tabular}{|c|c|c|c|c|}
\hline $\begin{array}{c}\mathrm{pH} \text {, ionic strength } \\
{[\mathrm{M}]}\end{array}$ & $\begin{array}{l}\text { Monolayer thickness OWLS } \\
{[\mathrm{nm}]}\end{array}$ & $\begin{array}{l}\text { Maximum coverage OWLS } \\
{\left[\mathrm{mg} \mathrm{m}^{-2}\right]}\end{array}$ & $\begin{array}{c}\text { Maximum coverage QCM } \\
{\left[\mathrm{mg} \mathrm{m}^{-2}\right]}\end{array}$ & $\begin{array}{c}\text { Maximum coverage theoretical } \\
{\left[\mathrm{mg} \mathrm{m}^{-2}\right]}\end{array}$ \\
\hline 3.5 & 5.7 & $0.90 \pm 0.1$ & $1.1 \pm 0.1$ & $0.82^{b}$ \\
\hline $10^{-2}$ & & & $1.2 \pm 0.1^{a}$ & side-on adsorption with crossings \\
\hline 4 & - & $(2.2-2.4) \pm 0.2$ & $2.0 \pm 0.2$ & $3.1^{b}$ \\
\hline $10^{-2}$ & & & & side-on afterward end-on \\
\hline 4/7.4 (pH jump) & not feasible & not feasible & $3.2 \pm 0.1$ & Side-on afterward end-on \\
\hline $10^{-2}$ & & & & 3.1 \\
\hline 7.4 & 21 & $4.3 \pm 0.2$ & $4.0 \pm 0.1$ & 4.1 \\
\hline $10^{-2}$ HEPES & & & $4.1 \pm 0.1^{a}$ & $\begin{array}{l}\text { side-on/end-on adsorption } \\
\text { simultaneously }\end{array}$ \\
\hline 7.4 & 20 & $(4.4-5.3) \pm 0.2$ & $4.0 \pm 0.1$ & 4.1 \\
\hline $0.15 \mathrm{NaCl}$ & & & & $\begin{array}{l}\text { side-on/end-on adsorption } \\
\text { simultaneously }\end{array}$ \\
\hline 7.4 & - & $4.2 \pm 0.2$ & - & 4.1 \\
\hline $0.15 \mathrm{M}$ HEPES & & & & $\begin{array}{l}\text { side-on/end-on adsorption } \\
\text { simultaneously }\end{array}$ \\
\hline
\end{tabular}

${ }^{a}$ Reference 34 silica QCM sensor (PBS buffer), dry mass coverage. ${ }^{b}$ Theoretical results calculated using the random sequential adsorption (RSA) model. ${ }^{13}$

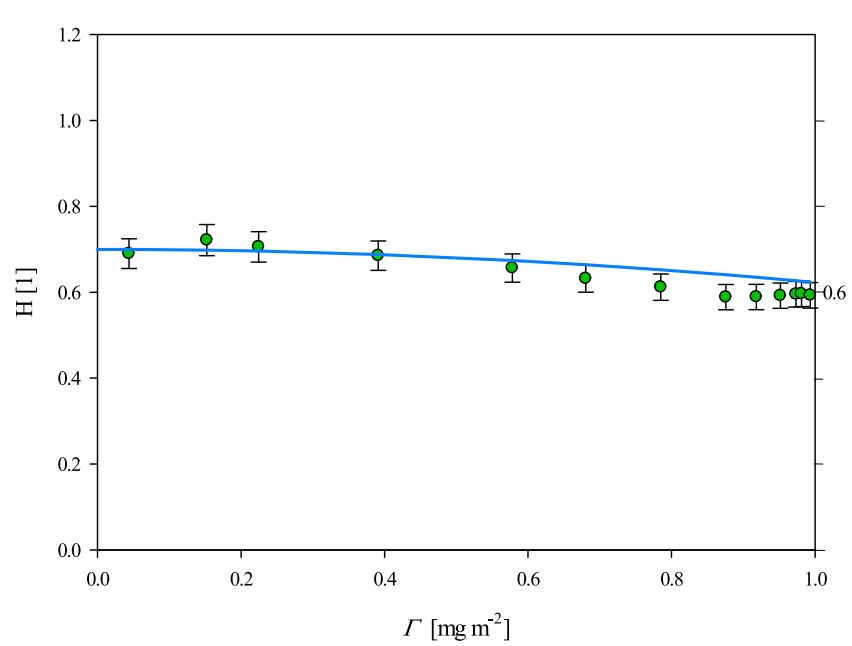

Figure 4. Dynamic hydration function for fibrinogen vs the dry coverage derived from OWLS (solid points): $\mathrm{pH} 3.5,0.01 \mathrm{M}, \mathrm{NaCl}$. The solid line shows the interpolation function given by eq 7 previously obtained in ref 34 at the same conditions.

solution of the mass transport equation. These data were interpolated using the following expression ${ }^{34}$

$$
H=H_{0}\left(1-C_{2} \Gamma^{2}\right)
$$

where $H_{0}=0.70$ is the hydration in the limit of zero coverage and $C_{2}=0.11 \mathrm{~m}^{4} \mathrm{mg}^{-2}$.

One can observe that the results derived from eq 7 agree within experimental error bounds with the presently obtained results data where the "dry" coverage was derived from OWLS.

Analogous measurements were performed for larger $\mathrm{pHs}$ (4 and 7.4) in order to determine the applicability of the OWLS method in the case where the formation of heterogeneous monolayers is expectedly composed of side-on and end-on adsorbed molecules as observed in previous work. ${ }^{34}$ A typical OWLS kinetic run obtained at $\mathrm{pH} 7.4$ stabilized by the HEPES buffer is presented in Figure 5a. Apparently, this run resembles the previous one shown in Figure 3a because initially, for the adsorption time below $5 \mathrm{~min}$ (where the fibrinogen coverage was smaller than $3 \mathrm{mg} \mathrm{m}^{-2}$ ), the adsorption kinetic remains a linear function of time. For $t>10 \mathrm{~min}$ the kinetics become considerably slower and a liming coverage equal to $4.5 \mathrm{mg} \mathrm{m}^{-2}$ is attained. Upon switching to desorption at the time of 30 min, a negligible decrease in the fibrinogen coverage is observed that amounts to ca. $0.2 \mathrm{mg} \mathrm{m}^{-2}$. Analogous kinetic runs obtained by QCM are shown in Figure 5b. In this case, the maximum fibrinogen coverage after performing the desorption run was equal to $13 \mathrm{mg} \mathrm{m}^{-2}$. Using the hydration function derived in ref 34 one can calculate from the QCM result that the dry coverage of fibrinogen is equal to $4.0 \mathrm{mg}$ $\mathrm{m}^{-2}$.

However, closer inspection of the OWLS experimental data shown in Figure 5a indicates for $t<10$ min they significantly deviate from previous kinetics shown in Figure 3a because the slope of the linear regime is equal to $1.8 \mathrm{mg} \mathrm{m}^{-2} \mathrm{~min}^{-1}$ that is 3.4 times larger than previously determined for $\mathrm{pH} 3.5$ (equal to $0.53 \mathrm{mg} \mathrm{m}^{-2} \mathrm{~min}^{-1}$ ) despite the fact that the bulk concentration of fibrinogen and the flow rate were the same. This deviation is above the experimental error limit and cannot be explained by an enhanced rate of protein molecule transport to the sensor because it cannot exceed the maximum value governed by the mass transfer rate constant $k_{c}$.

In order to analyze this point in more detail, the results obtained for $\mathrm{pH} 7.4$ are shown in Figure 6 for shorter times (below $300 \mathrm{~s}$ ) and they are compared with the QCM experimental data (transformed to the dry mass using the hydration function given in ref 34) and with theoretical predictions derived from eq 5 using the hybrid RSA model. One can observe that the OWLS results calculated using the homogeneous layer model significantly overestimate the experimental QCM data that agree with the theoretical results. Moreover, the OWLS kinetics are characterized by a nonlinear dependence of the coverage on the adsorption time that is evidently nonphysical given that the blocking effects are negligible for this range of fibrinogen coverage. Only at the adsorption time over $100 \mathrm{~s}$, where the true fibrinogen coverage is above $1 \mathrm{mg} \mathrm{m}^{-2}$, the OWLS slope approaches the theoretical and the QCM slope. A most probable explanation of the limited accuracy of the OWLS method for the lower coverage range can be sought in the large heterogeneity of the adsorbed fibrinogen layer that is predicted from the modeling. ${ }^{13}$ It is demonstrated (see the Supporting Information) that the coverage of fibrinogen molecules adsorbed in end-on 
a)

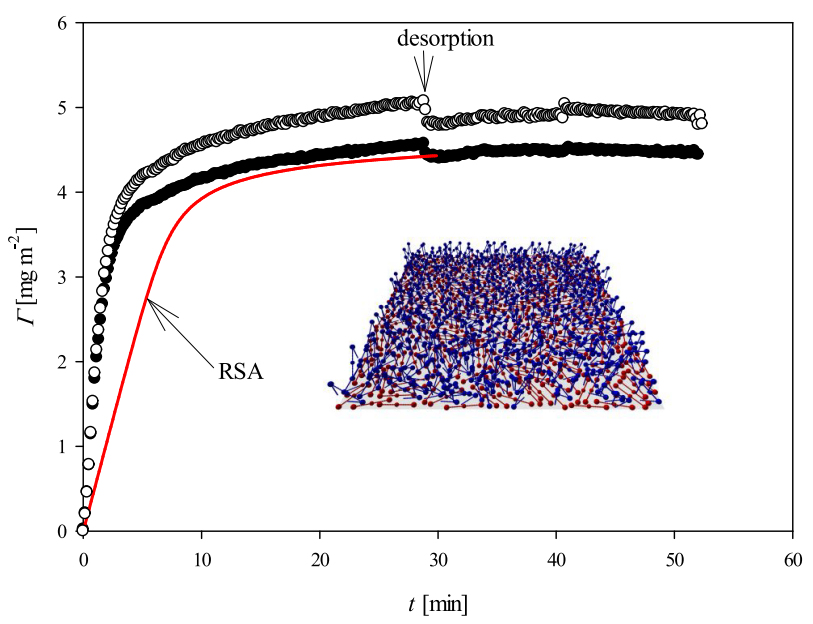

b)

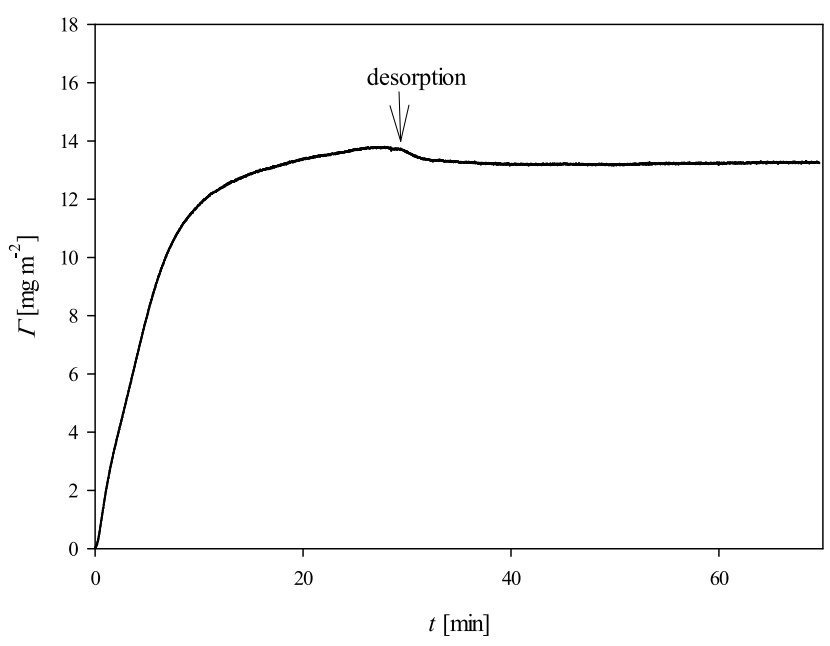

Figure 5. Kinetics of fibrinogen adsorption/desorption on silica sensors; bulk protein concentration $10 \mathrm{mg} \mathrm{L}^{-1}, \mathrm{pH} 7.4,0.01 \mathrm{M} \mathrm{NaCl}$, flow rate $2.5 \times 10^{-3} \mathrm{~cm}^{3} \mathrm{~s}^{-1}$. (a) OWLS measurements; the open symbols show the fibrinogen mass coverage calculated according to the numerical procedure described in ref 56, and the full symbols show the results calculated using the homogeneous and isotropic adlayer model and isotropic adlayers. The red solid line shows the theoretical results derived by numerical integration of eq 6 . The inset $(1000 \mathrm{~nm} \times 1000 \mathrm{~nm})$ shows the fibrinogen molecule monolayer derived from RSA modeling (side-on adsorbed molecules are depicted by a red color and end-on adsorbed molecules by a blue color). (b) QCM measurements. In both cases, the arrows show the beginning of the desorption run.

orientations only exceeds the coverage of side-on adsorbed molecules for the total coverage above $1 \mathrm{mg} \mathrm{m}^{-2}$. Only for such a coverage range the fibrinogen monolayer becomes significantly more uniform.

Consequently, the maximum coverage derived from OWLS that is equal to $4.3 \mathrm{mg} \mathrm{m}^{-2}$ agrees within the experimental error bound with the maximum coverage derived from QCM equal to $4.1 \mathrm{mg} \mathrm{m}^{-2}$ (see Table 1). It should be mentioned that an analogous effect was observed at $\mathrm{pH} 4$, where the initial OWLS slope was equal to $2.1 \mathrm{mg} \mathrm{m}^{-2} \mathrm{~min}^{-1}$ and the maximum coverage was equal to $2.2 \mathrm{mg} \mathrm{m}^{-2}$. These facts suggest that the

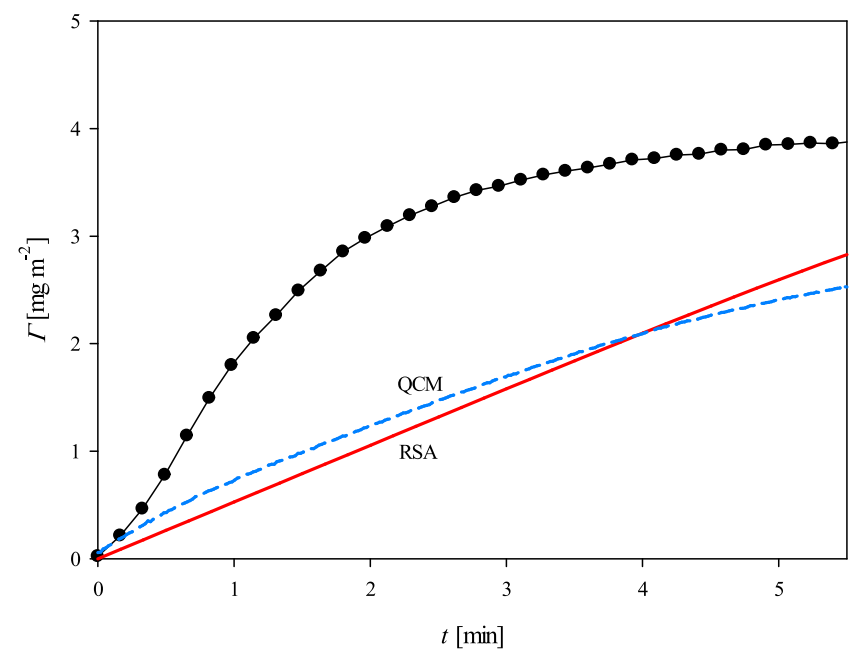

Figure 6. Kinetics of fibrinogen adsorption on silica; bulk protein concentration $10 \mathrm{mg} \mathrm{L}^{-1}$, HEPES concentration $0.01 \mathrm{M}, \mathrm{pH} 7.4$, flow rate $2.5 \times 10^{-3} \mathrm{~cm}^{3} \mathrm{~s}^{-1}$. Solid points show OWLS measurements interpolated by the black line. The dashed blue line shows the QCM results converted to dry mass using the hydration function derived from eq 7 , and the solid red line shows the theoretical results derived by numerical integration of eq 6 for the irreversible side-on adsorption with crossings.

homogeneous layer model becomes inadequate for protein molecules characterized by large anisotropy, especially for the lower coverage range, where the monolayer is heterogeneous. Horvath et al. ${ }^{45}$ have predicted some errors in the refractive index, thickness, and adsorbed mass when the anisotropic film are treated as isotropic. A more refined model which considers anisotropy of the refractive index is needed as previously suggested by Kovacs et al. ${ }^{44}$

However, the OWLS technique can yield reliable maximum coverage data, which is confirmed by the agreement of the OWLS, QCM, and theoretical predictions derived from the RSA model; see Table 1.

Although a quantitative calculation of the interaction energy is not feasible because of the complicated shape of the fibrinogen molecule, it is useful to carry out an interpretation of these maximum coverage data in terms of electrostatic interactions. At $\mathrm{pH} 3.5$ the zeta potential of the fibrinogen molecule is equal to $25 \mathrm{mV}$ (at the ionic strength of $0.01 \mathrm{M}$ ) and the silica substrate is slightly negative, equal to $-15 \mathrm{mV}$. Considering this and the fibrinogen molecule length $75 \mathrm{~nm}$ (in the expanded state) one can estimate using the formula pertinent to the spheroid molecules shape ${ }^{54}$ that the electrostatic attraction energy in the side-on orientation of the molecule at the distance of $0.5 \mathrm{~nm}$ is ca. $-25 \mathrm{kT}$. The van der Waals interaction energy at this distance is ca. $-5 \mathrm{kT}$. The sum of these energies definitely ensures an irreversible adsorption of fibrinogen molecules in the side-on orientation but not in the end-on orientation where the molecule contact length with the surface is only $18 \mathrm{~nm}$. Consequently, one can predict that the side-on adsorption should prevail which is characterized by theoretical maximum coverage of $0.82 \mathrm{mg}$ $\mathrm{m}^{-2}$ (Supporting Information). This is close to the experimental OWLS value of $0.90 \mathrm{mg} \mathrm{m}^{-2}$. However, the zeta potential of the silica substrate rapidly decreases with $\mathrm{pH}$, attaining $-25 \mathrm{mV}$ at $\mathrm{pH} \mathrm{4}$, whereas the zeta potential of fibrinogen only slightly decreases to ca. $18 \mathrm{mV}$ (at the ionic strength of $0.01 \mathrm{M}$ ). Thus, at $\mathrm{pH}>3.5$, the interaction energy 
may become sufficient to immobilize some fibrinogen molecules in the end-on orientation especially at the local spots bearing a more negative surface charge. As a result, the maximum coverage at $\mathrm{pH} 4$ increases to ca. $2 \mathrm{mg} \mathrm{m}^{-2}$ that is close to the average of the side-on and end-on orientations predicted theoretically (see Table 1 ).

In contrast, the results obtained at $\mathrm{pH} 7.4$ where the maximum coverage of fibrinogen is equal to $4.3 \mathrm{mg} \mathrm{m}^{-2}$ at are in contradiction with the theoretical prediction derived from the mean-field theory because both the zeta potentials of the fibrinogen molecule and the silica substrate are negative and equal to -30 and $-60 \mathrm{mV}$, respectively. This discrepancy was previously explained ${ }^{12,26}$ considering a largely heterogeneous charge distribution on the fibrinogen molecule. Hence the side arms ( $\alpha \mathrm{C}$ chains) are positively charged for the entire $\mathrm{pH}$ range whereas the core part of the molecule remains negatively charged (see the Supporting Information). In this way, adsorbing fibrinogen molecules can form electrostatic bonds with the substrate surface provided that its charge density is sufficiently large and negative. Consequently, the molecules can irreversibly adsorb under both the side-on and end-on orientations with the theoretically predicted maximum coverage equal to $4.1 \mathrm{mg} \mathrm{m}^{-2}$ that agrees with the experimental value (see Table 1 ).

It is interesting to mention that the results obtained in this work at $\mathrm{pH} 7.4$ agree with previous literature data obtained by Santore and Wertz ${ }^{22}$ who determined using the TIRF method that the maximum coverage of fibrinogen is equal to $4.1 \mathrm{mg}$ $\mathrm{m}^{-2}$ (silica and glass slides, $\mathrm{pH} 7.4$, phosphate and carbonate buffer). Analogously Höök et al., ${ }^{20}$ using ellipsometry, obtained the value of $3.97 \mathrm{mg} \mathrm{m}^{-2}$ for titanium oxide surfaces ( $\mathrm{pH} 7.4$, HEPES buffer, ionic strength $10^{-2} \mathrm{M}$ ) and $4.5 \mathrm{mg}$ $\mathrm{m}^{-2}$ using OWLS. Malmsten ${ }^{21}$ obtained $4 \mathrm{mg} \mathrm{m}^{-2}$ for methylated silica (ellipsometry, $\mathrm{pH}$ 7.4, phosphate buffer, ionic strength $0.15 \mathrm{M}$ ).

A decisive role of the electrostatic interaction is confirmed by composite fibrinogen adsorption experiments performed using QCM where $\mathrm{pH}$ was abruptly changed from 4 to 7.4 with all other parameters remaining unchanged (analogous measurements by OWLS are not feasible because of too slow response of the detector system to $\mathrm{pH}$ variations). The results shown in Figure 7 indicate that the $\mathrm{pH}$ jump enhances the fibrinogen adsorption that attains ca. $10 \mathrm{mg} \mathrm{m}^{-2}$ after performing the desorption run. This corresponds to the dry fibrinogen coverage of $3.2 \mathrm{mg} \mathrm{m}^{-2}$ that almost matches the theoretical result predicted for the side-on followed by end-on adsorption mechanism by the maximum coverage, which was equal to $3.1 \mathrm{mg} \mathrm{m}^{-2}$.

\section{CONCLUSIONS}

The main goal of this work was determining the range of applicability of the OWLS method to perform thorough experimental measurements for fibrinogen whose molecule exhibits a largely anisotropic shape. The experimental data are quantitatively interpreted in terms of the hybrid random sequential adsorption (RSA) model, which yields the kinetics and the maximum protein coverage pertinent to various orientations of adsorbing molecules. This enabled confirmation of the appearance of different, $\mathrm{pH}$-dependent mechanisms of fibrinogen adsorption on silica substrates. At $\mathrm{pH} 3.5$, the molecules mostly adsorb in the side-on orientation that produces a low maximum coverage of ca. $1 \mathrm{mg} \mathrm{m}^{-2}$. At this $\mathrm{pH}$, the kinetics derived from the OWLS measurements agree

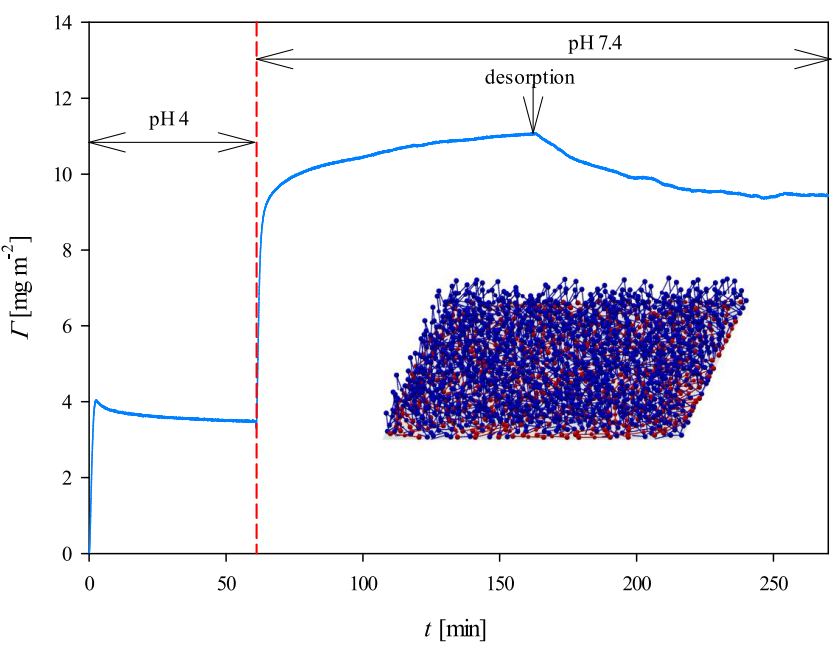

Figure 7. Kinetics of fibrinogen adsorption on silica derived from composite QCM measurements; bulk protein concentration $10 \mathrm{mg}$ $\mathrm{L}^{-1}, \mathrm{NaCl}$ concentration $0.01 \mathrm{M}$, flow rate $2.5 \times 10^{-3} \mathrm{~cm}^{3} \mathrm{~s}^{-1}$. At the time of $60 \mathrm{~min}$, the initial $\mathrm{pH}$ of 4 was abruptly changed to $\mathrm{pH}$ 7.4. The inset $(1000 \mathrm{~nm} \times 1000 \mathrm{~nm})$ shows the fibrinogen monolayer derived from RSA modeling: first adsorption in the side-on orientation at $\mathrm{pH} 4$ (red color) and afterward in the end-on orientation at $\mathrm{pH} 7.4$ (blue color).

with those theoretically predicted using the convectivediffusion theory considering the flow pattern in the cell. Consequently, a comparison of the OWLS and QCM results allows the water factor and the dynamic hydration of fibrinogen molecules for the entire range of coverage to be determined. The results obtained in this way agree with previous data obtained in ref 34 where the fibrinogen hydration degree was calculated considering theoretical data derived from the RSA model.

However, at larger pHs, especially $\mathrm{pH} 7.4$, the OWLS method yields less accurate kinetic data for the low coverage range but the maximum coverage agrees with the QCM results and with previous literature results. It is postulated that the limited precision of the OWLS method for the lower coverage range stems from the use of the thin adlayer model assuming its homogeneous and isotropic structure.

In reality, at $\mathrm{pH}>3.5$ except for the side-on, there appears a fraction of end-on adsorbed fibrinogen molecules whose coverage monotonically increases with the time. This renders the monolayer structure heterogeneous for the transient coverage range. Only at the coverage approaching the maximum one (that was equal to $4.4 \mathrm{mg} \mathrm{m}^{-2}$ at $\mathrm{pH} 7.4$ ) the monolayer becomes homogeneous and the OWLS gives more precise results that agree with QCM (considering hydration) and with previous experimental data reported in the literature.

Therefore, it is suggested that in order to increase the OWLS technique performance, future research should be concentrated on developing an adequate theoretical model for anisotropic protein layers.

One can also conclude that the results presented in this work, besides significance to basic science, allow to develop a robust procedure for preparing fibrinogen layers of wellcontrolled coverage and molecule orientation. Such fibrinogen platforms could be used in diagnostic test for the determination of active agents, e.g., polypeptides or immunoglobulins at ultralow level. 


\section{ASSOCIATED CONTENT}

\section{S Supporting Information}

The Supporting Information is available free of charge on the ACS Publications website at DOI: 10.1021/acs.langmuir.9b01341.

Modeling of fibrinogen monolayers and adsorption kinetics (PDF)

\section{AUTHOR INFORMATION}

\section{Corresponding Authors}

*E-mail: ncwasile@cyf-kr.edu.pl. Phone: +4812 6395129. Fax: +4812 4251923 .

*E-mail: ncadamcz@cyf-kr.edu.pl. Phone: +4812 6395104. Fax: +48124251923.

\section{ORCID $\odot$}

Monika Wasilewska: 0000-0003-2169-0568

Zbigniew Adamczyk: 0000-0002-8358-3656

Fouzia Boulmedais: 0000-0002-4934-9276

Michał Cieśla: 0000-0002-1191-0718

Notes

The authors declare no competing financial interest.

\section{ACKNOWLEDGMENTS}

This work was financially supported by the National Research Center Research projects: UMO-2014/13/D/ST4/01846 and UMO-2015/19/B/ST5/00847 (theoretical modeling, interpretation of experimental data). We would like to thank Robert Horvath and Andras Saftics from Nanobiosensoric Laboratory MTA EK MFA, Budapest, Hungary for valuable discusions during data analysis.

\section{REFERENCES}

(1) Grunkemeier, J. M.; Tsai, W. B.; McFarland, C. D.; Horbett, T. A. The effect of adsorbed fibrinogen, fibronectin, von Willebrand factor and vitronectin on the procoagulant state of adherent platelets. Biomaterials 2000, 21, 2243-2252.

(2) Gorbet, M. B.; Sefton, M. V. Biomaterial-associated thrombosis: roles of coagulation factors, complement, platelets and leukocutes. Biomaterials 2004, 25 (26), 5681-5703.

(3) Blombäck, B. Fibrinogen and fibrin-proteins with complex roles in hemostasis and thrombosis. Thromb. Res. 1996, 83, 1-75.

(4) Mosesson, M. W. Fibrinogen and fibrin structure and functions. J. Thromb. Haemostasis 2005, 3, 1894-1904.

(5) Watt, K. W. K.; Takagi, T.; Doolittle, R. F. Amino acid sequence of the $\beta$ chain of human fibrinogen: homology with the $\gamma$ chain. Proc. Natl. Acad. Sci. U. S. A. 1978, 75, 1731-1735.

(6) Jung, S. Y.; Lim, S. M.; Albertorio, F. The Vroman effect: A molecular level description of fibrinogen displacement. J. Am. Chem. Soc. 2003, 125, 12782-12786.

(7) Yu, S.; Sher, B.; Kudryk, B.; Redman, C. M. Fibrinogen precursors. Order of assembly of fibrinogen chains. J. Biol. Chem. 1984, 259, 10574-10581.

(8) Hall, C. E.; Slayter, H. S. The fibrinogen molecule: its size, shape, and mode of polymerization. J. Cell Biol. 1959, 5, 11-16.

(9) Veklich, Y. I.; Gorkun, O. V.; Medved, L. V.; Nieuwenhuizen, W.; Weisel, J. W. Carboxyl-terminal portion of the alpha chains of fibrinogen and fibrin. Localization by electron microscopy and the effects of isolated alpha $\mathrm{C}$ fragments on polymerization. J. Biol. Chem. 1993, 268, 13577-13585.

(10) Yermolenko, L. S.; Gorkun, O. V.; Fuhrmann, A.; Podolnikova, N. P.; Lishko, V. K.; Oshkadyerov, S. P.; Lord, S. T.; Ros, R.; Ugorova, T. P. The assembly of nonadhesive matrices depends on the $\alpha \mathrm{C}$ regions of the fibrinogen molecule. J. Biol. Chem. 2012, 287, 41979-41990.
(11) Protopopova, A. D.; Litvinov, R. I.; Galanakis, D. K.; Nagaswami, C.; Barinov, N. A.; Mukhitov, A. R.; Klinov, D. V.; Weisel, J. W. Morphometric characterization of fibrinogen's $\alpha \mathrm{C}$ regions and their role in fibrin self-assembly and molecular organization. Nanoscale 2017, 9, 13707-13716.

(12) Adamczyk, Z.; Cichocki, B.; Ekiel-Jezewska, M. L.; Słowicka, A.; Wajnryb, E.; Wasilewska, M. Fibrinogen conformations and charge in electrolyte solutions derived from DLS and dynamic viscosity measurements. J. Colloid Interface Sci. 2012, 385, 244-257.

(13) Cieśla, M.; Adamczyk, Z.; Barbasz, J.; Wasilewska, M. Mechanisms of fibrinogen adsorption at solid substrates at lower pH. Langmuir 2013, 29, 7005-7016.

(14) Nattich-Rak, M.; Adamczyk, Z.; Wasilewska, M.; Sadowska, M. Fibrinogen monolayer characterization by colloid deposition. Langmuir 2013, 29, 11991-12002.

(15) Ortega-Vinuesa, J. L.; Tengvall, P.; Lundström, I. Molecular packing of HSA, IgG, and fibrinogen adsorbed on silicon by AFM imaging. Thin Solid Films 1998, 324, 257-273.

(16) Nakanishi, K.; Sakiyama, T.; Imamura, K. On the adsorption of proteins on solid surfaces, a common but very complicated phenomenon. J. Biosci,Bioeng. 2001, 91, 233-244.

(17) Grunkemeier, J. M.; Tsai, W. B.; McFarland, C. D.; Horbett, T. A. The effect of adsorbed fibrinogen, fibronectin, von Willebrand factor and vitronectin on the procoagulant state of adherent platelets. Biomaterials 2000, 21, 2243-2252.

(18) Flick, M. J.; Du, X.; Witte, D. P.; Jirousková, M.; Soloviev, D. A.; Busuttil, S. J.; Plow, E. F.; Degen, J. L. Leukocyte engagement of fibrin(ogen) via the integrin receptor alphaM/beta2/Mac-1 is critical for host inflammatory response in vivo. J. Clin. Invest. 2004, 113, $1596-1606$.

(19) Hantagan, R. R.; Simpson-Haidaris, P. J.; Francis, C. W.; Marder, V. J. Fibrinogen Structure and Physiology. In Hemostasis and Thrombosis: Basic Principles and Clinical Practice; Coleman, R. W., Hirsh, J., Marder, V. J., Clowes, A. W., George, J., Eds.;Lippincott Williams \& Wilkins: Philadelphia, 2000; pp 203-232.

(20) Höök, F.; Vörös, J.; Rodahl, M.; Kurrat, R.; Böni, P.; Ramsden, J. J.; Textor, M.; Spencer, N. D.; Tengvall, P.; Gold, J.; Kasemo, B. Acomparative study of protein adsorption on titanium oxide surfaces using in situ ellipsometry, optical waveguide lightmode spectroscopy, and quartz crystal microbalance/dissipation. Colloids Surf., B 2002, 24, 155-170.

(21) Malmsten, M. Ellipsometry studies of protein layers adsorbed at hydrophobic surfaces. J. Colloid Interface Sci. 1994, 166, 333-342.

(22) Santore, M. M.; Wertz, C. F. Protein spreading kinetics at liquid-solid interfaces via an adsorption probe method. Langmuir 2005, 21, 10172-10178.

(23) Dyr, J. E.; Suttnar, J. Molecular arrangement of adsorbed fibrinogen molecules characterized by specific monoclonal antibodies and a surface plasmon resonance sensor. Sens. Actuators, B 1998, 51, 268-272.

(24) Sit, P. S.; Marchant, R. E. Surface-dependent conformations of human fibrinogen observed by atomic force microscopy under aqueous conditions. Thromb. Haemostasis 1999, 82, 1053-1060.

(25) Marchin, K. L.; Berrie, C. L. Conformational changes in the plasma protein fibrinogen upon adsorption to graphite and mica investigated by atomic force microscopy. Langmuir 2003, 19, 98839888.

(26) Wasilewska, M.; Adamczyk, Z. Fibrinogen adsorption on mica studied by AFM and in situ streaming potential measurements. Langmuir 2011, 27 (27), 686-696.

(27) Bingen, P.; Wang, G.; Steinmetz, N. F.; Rodahl, M.; Richter, R. $\mathrm{P}$. Solvation effects in the quartz crystal microbalance with dissipation monitoring response to biomolecular adsorption. A phenomenological approach. Anal. Chem. 2008, 80, 8880-8890.

(28) Carton, I.; Brisson, A. R.; Richter, R. P. Label-free detection of clustering of membrane-bound proteins. Anal. Chem. 2010, 82, 92759281.

(29) Reviakine, I.; Johannsmann, D.; Richter, R. P. Hearing what you cannot see and visualizing what you hear: interpreting quartz 
crystal microbalance data from solvated interfaces. Anal. Chem. 2011, 83, 8838-8848.

(30) Srokowski, E. M.; Woodhousse, K. A. Evaluation of the bulk platelet response and fibrinogen interaction to elastin-like polypeptide coatings. J. Biomed. Mater. Res. Part A 2013, 102A, 540-551.

(31) Hu, Y.; Jin, J.; Han, Y.; Yin, J.; Jiang, W.; Liang, H. Study of fibrinogen adsorption on poly(ethylene glycol)-modified surfaces using a quartz crystal microbalance with dissipation and a dual polarization interferometry. RSC Adv. 2014, 4, 7716-7724.

(32) Lord, M. S.; Whitelock, J. M.; Simmons, A.; Williams, R. L.; Milthorpe, B. K. Fibrinogen adsorption and platelet adhesion to silica surfaces with stochastic nanotopography. Biointerphases 2014, 9, 041002-1-041002-11.

(33) Adamczyk, Z.; Pomorska, A.; Nattich-Rak, M.; Wytrwal-Sarna, M.; Bernasik, A. Protein adsorption mechanisms at rough surfaces: Serum albumin at a gold substrate. J. Colloid Interface Sci. 2018, 530, 631-641.

(34) Kubiak, K.; Adamczyk, Z.; Wasilewska, M. Mechanisms of fibrinogen adsorption at the silica substrate determined by QCM-D measurements. J. Colloid Interface Sci. 2015, 457, 378-387.

(35) Pomorska, A.; Adamczyk, Z.; Nattich-Rak, M.; Sadowska, M. Kinetics of human serum albumin adsorption at silica sensor: Unveiling dynamic hydration function. Colloids Surf., B 2018, 167, 377-384.

(36) Vörös, J.; Ramsden, J. J.; Csúcs, G.; Szendrő, I.; De Paul, S. M.; Textor, M.; Spencer, N. D. Optical grating coupler biosensor. Biomaterials 2002, 23, 3699-3710.

(37) Grandin, H. M.; Stadler, B.; Textor, M.; Voros, J. Waveguide excitation fluorescence microscopy: A new tool for sensing and imaging the biointerface. Biosens. Bioelectron. 2006, 21, 1476-1482.

(38) Wittmer, C. R.; Phelps, J. A.; Saltzman, W. M.; Van Tassel, P. R. Fibronectin terminated multilayer films: Protein adsorption and cell attachement studies. Biomaterials 2007, 28, 851-860.

(39) Stadler, B.; Falconnet, D.; Pfeiffer, I.; Hook, F.; Vörös, J. Micropatterning of DNA-Tagged vesicles. Langmuir 2004, 20, $11348-11354$.

(40) Hug, T. S. Biophysical methods for monitoring cell-substrate interactions in drug discovery. Assay Drug Dev. Technol. 2003, 1, 479488.

(41) Grieshaber, D.; Reimhult, E.; Vörös, J. Enzymatic biosensors towards a multiplexed electronic detection system for early cancer diagnostics. Nano/Micro engineered and molecular systems, 2007, NEMS 07 2nd IEEE international conference; 2007; pp 402-405.

(42) Kurrat, R.; Prenosil, J. E.; Ramsden, J. J. Kinetics of human and bovine serum albumins adsorption at silica-titania surfaces. J. Colloid Interface Sci. 1997, 185, 1-8.

(43) Sander, M.; Madliger, M.; Schwarzenbach, R. P. Adsorption of transgenic insecticidal CrylAb protein to $\mathrm{SiO}_{2}$. 1 . Forces driving adsorption. Environ. Sci. Technol. 2010, 44, 8870-8876.

(44) Kovacs, N.; Patko, D.; Orgovan, N.; Kurunczi, S.; Ramsden, J. J.; Vonderviszt, F.; Horvath, R. Optical anisotropy of flagellin layers: In situ and label-free measurements of adsorbed protein orientation using OWLS. Anal. Chem. 2013, 85, 5382-5389.

(45) Horvath, R.; Ramsden, J. J. Quasi-isotropic analysis of anisotropic thin films on optical waveguids. Langmuir 2007, 23, 9330-9334.

(46) Kovacs, B.; Saftics, A.; Biro, A.; Kurunczi, S.; Szalontai, B.; Kakasi, B.; Vonderviszt, F.; Der, A.; Horvath, R. Kinetics and structure of self-assembled flagellin monolayers on hydrophobic surfaces in the presence of Hofmeister salts: Experimental measurements of the protein interfacial tension at the nanometer scale. J. Phys. Chem. C 2018, 122, 21375-21386.

(47) Kovacs, B.; Horvath, R. Modeling of Label-free optical waveguide biosensors with surfaces covered partially by vertically homogeneous and inhomogeneous films. J. Sens. 2019, 2019, 1-11.

(48) Vörös, J. The density and refractive index of adsorbing protein layers. Biophys. J. 2004, 87, 553-561.
(49) Kubiak, K.; Adamczyk, Z.; Cieśla, M. Fibrinogen adsorption mechanisms at the gold substrate revealed by QCM-D measurements and RSA modeling. Colloids Surf., B 2016, 139, 123-131.

(50) Kubiak, K.; Adamczyk, Z.; Oćwieja, M. Kinetics of silver nanoparticle deposition at PAH monolayers: Reference QCM results. Langmuir 2015, 31, 2988-2996.

(51) Porus, M.; Maroni, P.; Borkovec, M. Structure of adsorbed polyelectrolyte monolayers investigated by combining optical reflectometry and piezoelectric techniques. Langmuir 2012, 28, $5642-5651$.

(52) Porus, M.; Maroni, P.; Borkovec, M. Response of adsorbed polyelectrolyte monolayers to changes in solution composition. Langmuir 2012, 28, 17506-17516.

(53) Wu, T.-H.; Liao, S.-Ch.; Chen, Y.-F.; Huang, Y.-Y.; Wei, Y.-S.; Tu, S.-J.; Chen, K.-S. Determination of functionalized gold nanoparticles incorporated in hydrophilic and hydrophobic microenvironments by surface modification of quartz crystal microbalance. Appl. Surf. Sci. 2013, 274, 418-424.

(54) Adamczyk, Z. Particles at Interfaces: Interactions, Deposition, Structure; Elsevier, Academic-Press: U.K., 2017.

(55) Wasilewska, M.; Adamczyk, Z.; Pomorska, A.; Nattich-Rak, M.; Sadowska, M. Human serum albumin adsorption kinetics on silica: Influence of protein solution stability. Langmuir 2019, 35, 26392648.

(56) Picart, C.; Gergely, C.; Arntz, Y.; Voegel, J.-C.; Schaaf, P.; Cuisinier, F.; Senger, B. Measurement of film thickness up to several hundreds of nanometers using optical waveguide lightmode spectroscopy. Biosens. Bioelectron. 2004, 20, 553-561. 